\title{
2030 Established cmr methods for left ventricular quantification differ based on variable exclusion of papillary/trabecular volumes: increased diagnostic impact among patients with left ventricular hypertrophy
}

\author{
Matthew Janik*, Matthew D Cham, Michael I Ross, Yi Wang, Noel Codella, \\ James K Min, Shant Manoughagian, Peter M Okin, Richard B Devereux and \\ Jonathan W Weinsaft
}

Address: New York Presbyterian Hospital - Weill Medical College of Cornell University, New York, NY, USA

* Corresponding author

from I I th Annual SCMR Scientific Sessions

Los Angeles, CA, USA. I-3 February 2008

Published: 22 October 2008

Journal of Cardiovascular Magnetic Resonance 2008, I0(Suppl I):A299 doi:10.1 186/1532-429X-10-SI-A299

This abstract is available from: http://jcmr-online.com/content//0/SI/A299

(c) 2008 Janik et al; licensee BioMed Central Ltd.

\section{Objective}

To assess the contribution of papillary muscles and trabeculae (PMT) to left ventricular (LV) quantification in patients with and without LV hypertrophy.

\section{Background}

Accurate assessment of left ventricular mass (LVM) and ejection fraction (EF) is of diagnostic importance for patients with LV hypertrophy (LVH). Cardiac magnetic resonance imaging (CMR) has been proposed as a standard for these indices. However, prior CMR studies have variably included papillary muscles/trabeculae (PMT) in intracavitary or myocardial volume. The relative impact of this methodologic variability on LVH patients is unknown.

\section{Methods}

Patients with established concentric (CLVH) or eccentric hypertrophy $(E L V H)$ independently verified by echocardiography were studied by CMR (1.5 T) and compared to a group of 20 low risk patients with normal LVM and geometry (NL). In all patients, short axis SSFP images were acquired contiguously through the LV (typical parameters: TR $3.5 \mathrm{msec}$, TE $1.6 \mathrm{msec}$, flip angle $60^{\circ}, 6 \mathrm{~mm}$ slice thickness $/ 4 \mathrm{~mm}$ gap). LV volumes were determined by two established methods: method 1 included PMT in myocardial volume, method 2 included PMT in intracavitary volume. Both methods were used for each patient with tracings superimposed to isolate PMT and ensure endocardial and epicardial contour consistency. Each method was applied blinded to results of the other technique.

\section{Results}

In the 60 total patients (40 LVH/20 NL), PMT accounted for $10.5 \%$ of total LVM, with over a 2 -fold difference between LVH and NL pts $(12.6$ vs $6.2 \%$, p < 0.001). LV mass quantification with PMT exclusion (method 2) produced a $37 \%$ reduction $(\mathrm{p}<0.001)$ in patients meeting gender-specific LVH criteria using previously established CMR definitions based on PMT inclusion (method 1). PMT correlated with LV wall mass $(r=0.67)$ and end diastolic volume (EDV) $(\mathrm{r}=0.68 ; \mathrm{p}<0.001)$. Method variability yielded differences in LVEF, EDV, and LVM within all groups (Table 1), but differences were greater in $\mathrm{LVH}$ patients: $\triangle$ LVM index was $>3$-fold greater in CLVH and $>$ 6 -fold greater in ELVH vs. NL $(\mathrm{p}<0.001)$. $\triangle \mathrm{EF}$ was $>2$ fold higher in CLVH vs. NL ( $\mathrm{p}<0.001)$. In multivariable analysis, $\triangle \mathrm{EF}$ was independently related to PMT mass, LV wall mass, and $\operatorname{EDV}\left(\mathrm{R}^{2}=0.56, \mathrm{p}<0.001\right)$. 
Table I: Methodological variance in LV volumetric and functional parameters

\begin{tabular}{|c|c|c|c|c|c|c|}
\hline & Normal & $\mathrm{P}$ & Eccentric LVH & $\mathrm{P}$ & Concentric LVH & $\mathrm{P}$ \\
\hline Myocardial Mass Index (g/m2) (method I) & $52.4 \pm 8.9$ & & $134.6 \pm 29.7$ & & $123.6 \pm 17.7$ & \\
\hline Myocardial Mass Index (g/m2) (method 2) & $49.4 \pm 9.0$ & & $113.7 \pm 26.0$ & & $111.6 \pm 15.2$ & \\
\hline$\Delta$ Myocardial Mass Index (g/m2) & $3.1 \pm 0.7$ & $<0.001$ & $20.9 \pm 8.9$ & $<0.001$ & $12.0 \pm 4.3$ & $<0.001$ \\
\hline Ejection Fraction (\%) (method I) & $68.2 \pm 6.4$ & & $21.8 \pm 9.2$ & & $59.8 \pm 15.1$ & \\
\hline Ejection Fraction (\%) (method 2 ) & $64.8 \pm 6.2$ & & $19.4 \pm 8.4$ & & $52.7 \pm 13.4$ & \\
\hline$\Delta$ Ejection Fraction (\%) & $3.4 \pm 1.0$ & $<0.001$ & $2.4 \pm 1.3$ & $<0.001$ & $7.1 \pm 13.4$ & $<0.001$ \\
\hline End Diastolic Volume (cc) (method I) & $134.8 \pm 39.9$ & & $282.5 \pm 60.1$ & & $137.9 \pm 27.8$ & \\
\hline End Diastolic Volume (cc) (method 2) & $140.4 \pm 40.6$ & & $320.5 \pm 70.6$ & & $160.1 \pm 27.8$ & \\
\hline$\Delta$ End Diastolic Volume (cc) & $5.6 \pm 1.7$ & $<0.001$ & $37.9 \pm 17.3$ & $<0.001$ & $22.2 \pm 7.4$ & $<0.001$ \\
\hline
\end{tabular}

\section{Conclusion}

Established CMR methods can yield differences in LV quantification due to variable exclusion of PMT from myocardium. Impact of PMT exclusion on calculated LVM and EF is increased in patients with hypertrophy-associated LV remodeling.

Publish with Biomed Central and every scientist can read your work free of charge

"BioMed Central will be the most significant development for disseminating the results of biomedical research in our lifetime. "

Sir Paul Nurse, Cancer Research UK

Your research papers will be:

- available free of charge to the entire biomedical community

- peer reviewed and published immediately upon acceptance

- cited in PubMed and archived on PubMed Central

- yours - you keep the copyright

Submit your manuscript here:

http://www.biomedcentral.com/info/publishing_adv.asp 